\title{
Ultrasound-Assisted Extraction of Anthocyanins from Haskap (Lonicera caerulea L.) Berries Using a Deep Eutectic Solvent (DES)
}

\author{
Amanda M.G. MacLean', \\ Yasmini P.A. Silva²®, \\ Guangling Jiao ${ }^{1}$ and \\ Marianne S. Brooks ${ }^{1 *}$ ( \\ 'Department of Process Engineering \\ and Applied Science, Dalhousie \\ University, 5273 DaCosta Row, PO \\ Box 15000, Halifax, NS, B3H 4R2, \\ Canada \\ ${ }^{2}$ Faculty of Nutrition, Federal \\ University of Goiás, Rua 227, qd. 68, \\ Setor Leste Universitário, Goiânia, \\ GO, 74605-080, Brazil
}

Received: 1 July 2020

Accepted: 10 February 2021

\begin{abstract}
SUMMARY
Research background. Haskap berries are one of the richest natural sources of anthocyanins and their extracts can be used for nutraceuticals and functional food ingredients. Deep eutectic solvents (DES) comprising food-grade or generally recognized as safe (GRAS) components show promise as natural solvents, but have not been applied to haskap berries. Thus, the aim of this study is to investigate the extraction of anthocyanins from haskap berries using a DES consisting of citric acid and D-(+)-maltose.

Experimental approach. The experimental approach used ultrasound-assisted extraction with a DES consisting of citric acid and D-(+)-maltose as the solvent to achieve a sustainable green extraction process. Response surface methodology (RSM) with a Box-Behnken experimental design was used to study the effect of varying the extraction temperature, time of extraction, $V($ solvent $) / m($ sample) ratio $(\mathrm{mL} / \mathrm{g})$ and the water volume fraction (\%) in the DES on the total anthocyanin content (TAC) in the haskap berry extracts.

Results and conclusions. Under the optimal extraction conditions $\left(75^{\circ} \mathrm{C}, 10 \mathrm{~min}, 50.4\right.$ $\mathrm{mL} / \mathrm{g}$ and $90 \%$ water), a predicted TAC extraction on dry mass basis yielded $21.2 \mathrm{mg} / \mathrm{g}$, with experimental error of $7.2 \%$. The TAC yield and anthocyanin profiles were similar to those obtained with conventional organic solvents.

Novelty and scientific contribution. This is the first study investigating the use of a food-grade DES comprising GRAS components for the extraction of anthocyanins from haskap berries. These results indicate that the studied DES (citric acid and D-(+)-maltose) is a suitable alternative solvent for extracting anthocyanins for food-grade applications.
\end{abstract}

Key words: anthocyanins, Box-Behnken design, deep eutectic solvent, green extraction, haskap

\section{INTRODUCTION}

Haskap (Lonicera caerulea L.) berries, a fruit native to Siberia and northeastern Asia, have recently entered the North American market (1) and are known for their high anthocyanin content (2). Anthocyanins are flavonoids associated with antioxidative, anti-inflammatory, and anticarcinogenic properties (3), and are highly desirable for their application as dietary supplements and natural colourants (4). Currently, they are extracted from natural sources using traditional solvents, such as methanol and ethanol (5).

The extraction of bioactive compounds from natural sources can be made more environmentally friendly with assisting technologies such as ultrasound to improve extraction efficiency (6) and the development of green solvents. Green solvents are alternatives to organic solvents, and may be non-petroleum derived, biodegradable, with low toxicity (7). Deep eutectic solvents (DES) can be produced by mixing two or more natural components capable of hydrogen bond interactions (8). DES have been used for extraction of several flavonoids, such as genistin, genistein and apigenin (9), icariin, catechin, (+)-catechin, quercetin, kaempferol, myricetin, quercetin-O-rhamnoside (10), rutin, a-mangostin and cryptotanshinone (11). Recently, the extraction of anthocyanins from grape skin $(12,13)$, wine lees (14) and Lycium ruthenicum Murr. fruit (15) using various DES has been reported.

\footnotetext{
*Corresponding author:

Phone: +1(902)494 6482

E-mail: su-ling.brooks@dal.ca
} 
The objective of this study is to investigate the ultrasound-assisted extraction (UAE) of anthocyanins from haskap berries using a DES prepared of citric acid and D-(+)-maltose as an alternative, sustainable, food-grade solvent. The extraction parameters studies were: temperature, time, water volume fraction in the DES and solvent to sample ratio. A Box-Benhken design of experiments and response surface methodology (RSM) were used to maximize anthocyanin extraction with DES, and the anthocyanin profile with DES extract was compared with a conventional methanol extract.

\section{MATERIALS AND METHODS}

\section{Chemicals}

All chemicals used were of analytical and high performance liquid chromatography (HPLC) grade, and were purchased from Sigma-Aldrich, Merck (Oakville, Ontario, Canada). The anthocyanin HPLC standards included cyanidin-3,5-diglucoside $(\mathrm{C} 3,5 \mathrm{GL})$, cyanidin-3-glucoside (C3GL), cyanidin-3-galactoside (C3GA), pelargonidin-3-glucoside (PL3GL) cyanidin-3-rutinoside (C3RT) and peonidin-3-O-glucoside (P3GL).

\section{Plant material}

Frozen haskap berries (Lonicera caerulea L.) that were previously harvested and frozen at Northern Light Orchards (Saskatchewan, Canada) were used. Berries were freeze dried in a 4.5-litre bench-top freeze-dryer (FreeZone, Labconco, Kansas City, MO, USA) until constant mass, with final moisture content of $4.95 \%$ (fresh mass). Freeze-dried samples were wrapped in aluminium foil and kept in a desiccator at $-18^{\circ} \mathrm{C}$. Immediately prior to extraction the samples were ground (Smartgrind, Black \& Decker, Mississauga, ON, Canada) and sieved through a $0.5-\mathrm{mm}$ (32 mesh) sieve.

\section{Solvent preparation}

The deep eutectic solvent (DES) was prepared according to Jeong et al. (13), with modifications. Briefly, citric acid and D-(+)-maltose monohydrate were combined at a 4:1 molar ratio in powdered form, and then dissolved in Milli-Q water (MilliporeSigma, Merck, Oakville, Canada). The solution was placed on a rotary evaporator (HiTEC RE-51; Yamato Scientific America, Santa Clara, CA, USA) at $4.2 \mathrm{kPa}$ and $50^{\circ} \mathrm{C}$ for elimination of excess water (16). Prior to extraction, the appropriate volume of DES was diluted with Milli-Q water (Table 1). The solvent was always prepared and used for extraction in the same day.

\section{Experimental design}

A Box-Behnken design for four factors (17) was used to determine the levels of the experimental parameters: extraction temperature in ${ }^{\circ} \mathrm{C}$, time of extraction in $\mathrm{min}$, water volume fraction in \%, and solvent/sample ratio $((\mathrm{V} / \mathrm{m}) /(\mathrm{mL} / \mathrm{g}))$ (Table 1). DES molar ratio was held constant at the optimized 4:1 citric acid/maltose ratio according to Jeong et al. (13).
Table 1. Box-Benhken experimental design with the levels for each investigated factor and resultant total anthocyanin content (TAC)

\begin{tabular}{|c|c|c|c|c|c|}
\hline $\begin{array}{c}\text { Run } \\
\text { number }\end{array}$ & $X_{1}$ & $\mathrm{X}_{2}$ & $x_{3}$ & $X_{4}$ & $\begin{array}{c}w(\text { TAC as C } 3 G \mathrm{G}) / \\
(\mathrm{mg} / \mathrm{g})\end{array}$ \\
\hline 1 & 25 & 10 & 60 & 35 & 19.04 \\
\hline 2 & 75 & 10 & 60 & 35 & 16.99 \\
\hline 3 & 25 & 60 & 60 & 35 & 17.42 \\
\hline 4 & 75 & 60 & 60 & 35 & * \\
\hline 5 & 50 & 35 & 30 & 10 & 5.02 \\
\hline 6 & 50 & 35 & 90 & 10 & 9.25 \\
\hline 7 & 50 & 35 & 30 & 60 & 15.66 \\
\hline 8 & 50 & 35 & 90 & 60 & 19.62 \\
\hline 9 & 25 & 35 & 60 & 10 & 7.75 \\
\hline 10 & 75 & 35 & 60 & 10 & 10.98 \\
\hline 11 & 25 & 35 & 60 & 60 & 12.07 \\
\hline 12 & 75 & 35 & 60 & 60 & 15.25 \\
\hline 13 & 50 & 10 & 30 & 35 & 12.83 \\
\hline 14 & 50 & 60 & 30 & 35 & 14.77 \\
\hline 15 & 50 & 10 & 90 & 35 & 18.24 \\
\hline 16 & 50 & 60 & 90 & 35 & 16.79 \\
\hline 17 & 25 & 35 & 30 & 35 & 7.99 \\
\hline 18 & 75 & 35 & 30 & 35 & 11.38 \\
\hline 19 & 25 & 35 & 90 & 35 & 9.79 \\
\hline 20 & 75 & 35 & 90 & 35 & 16.20 \\
\hline 21 & 50 & 10 & 60 & 10 & 10.21 \\
\hline 22 & 50 & 60 & 60 & 10 & 8.99 \\
\hline 23 & 50 & 10 & 60 & 60 & 14.64 \\
\hline 24 & 50 & 60 & 60 & 60 & 16.69 \\
\hline 25 & 50 & 35 & 60 & 35 & 16.39 \\
\hline 26 & 50 & 35 & 60 & 35 & 15.23 \\
\hline 27 & 50 & 35 & 60 & 35 & 18.46 \\
\hline 28 & 50 & 35 & 60 & 35 & 16.61 \\
\hline 29 & 50 & 35 & 60 & 35 & 16.17 \\
\hline 30 & 50 & 35 & 60 & 35 & 16.05 \\
\hline $\begin{array}{l}\text { Optimized } \\
\text { condition }\end{array}$ & 75 & 10 & 90 & 50.4 & $19.8^{* *}$ \\
\hline
\end{tabular}

Run number is not indicative of experimental run order. ${ }^{*}$ Data omitted; ** Predicted yield: $w($ TAC as $C 3 G L)=21.2 \mathrm{mg} / \mathrm{g} \mathrm{dm}$. $\mathrm{X}_{1}=$ temperature $/{ }^{\circ} \mathrm{C}, \mathrm{X}_{2}=t / \mathrm{min}, \mathrm{X}_{3}=\varphi($ water $) / \%, \mathrm{X}_{4}=(V($ solvent $) /$ $m($ sample) $) /(\mathrm{mL} / \mathrm{g})$

\section{Ultrasound-assisted extraction of anthocyanins}

Ultrasound-assisted extraction (UAE) was performed in an ultrasound water bath (Branson 2510R-DTH; Branson UItrasonics Corp., Danbury, CT, USA) at $40 \mathrm{kHz}$ and $100 \mathrm{~W}$. Extractions were conducted in 5-mL glass tubes, where the appropriate mass of sample and volume of solvent were added according to the Box-Behnken design (Table 1). The tubes were covered with aluminium foil, vortexed for $10 \mathrm{~s}$ and placed in the ultrasonic bath. Following extraction, samples were centrifuged (Sorvall RT1; Thermo Scientific, Madison, WI, USA) at $4{ }^{\circ} \mathrm{C}$ and $4000 \mathrm{rpm}$ for $10 \mathrm{~min}$. The supernatant was then filtered through a $0.45-\mu \mathrm{m}$ syringe filter and immediately used for spectrophotometric analysis (18). For comparison with DES, methanol extraction was conducted using the following optimal parameters based on a similar study using a conventional organic solvent by Celli et al. (18): solvent/ 
sample ratio $25: 1(\mathrm{~mL} / \mathrm{g})$, solvent composition $80 \%$ methanol solution and $0.5 \%$ formic acid, and extraction temperature $35^{\circ} \mathrm{C}$ for $20 \mathrm{~min}$.

\section{Determination of total monomeric anthocyanin content}

Total anthocyanin content (TAC) was determined using the $\mathrm{pH}$ differential method (19) conducted in duplicate using a UV-Visible spectrophotometer (Genesys 10S UV-Vis; Thermo Scientific). The TAC of the extract was calculated using the following equations:

and

$$
\begin{gathered}
A=\left(A_{510 \mathrm{~nm} \text { at } \mathrm{pH}=1.0}-A_{700 \mathrm{~nm} \text { at } \mathrm{pH}=1.0}\right)- \\
-\left(A_{510 \mathrm{~nm} \text { at } \mathrm{pH}=4.5}-A_{700 \mathrm{~nm} \text { at } \mathrm{pH}=4.5}\right)
\end{gathered}
$$

$$
\mathrm{TAC}=\left(A \cdot M \cdot \mathrm{DF} \cdot 10^{3}\right) /(\varepsilon \cdot l)
$$

where $A_{510 \mathrm{~nm} \text { at pH=1.0 }}$ and $A_{700 \mathrm{~nm} \text { at pH=1.0 }}$ are the absorbances of the solution adjusted to $\mathrm{pH}=1.0$ with $\mathrm{KCl}$ and $A_{510 \mathrm{~nm} \text { at } \mathrm{pH}=4.5}$ and $A_{700 \mathrm{~nm} \text { at } \mathrm{pH}=4.5}$ are the absorbances of the solution adjusted to $\mathrm{pH}=4.5$ with $\mathrm{NaAc}$, each read at 510 and $700 \mathrm{~nm}$, respectively, $A$ is the absorbance value from Eq. 1, $M$ is the molecular mass of $449.38 \mathrm{~g} / \mathrm{mol}$, DF is the dilution factor of $25, \varepsilon$ is molar absorption coefficient $26900 \mathrm{M}^{-1} \mathrm{~cm}^{-1}$ and / is path length $(1 \mathrm{~cm})$ (3). Results are expressed in $\mathrm{mg}$ of C3GL equivalents per $\mathrm{g}$ dry mass $(\mathrm{dm})$ of haskap berries.

\section{RSM analysis and optimization}

$\operatorname{Minitab}^{\circledast}$ (v. 17.3.1) was used for analysis (20). A polynomial model was fitted to the experimental results followed by backwards elimination to reduce the model to significant factors. The model was then analysed using analysis of variance (ANOVA) with a 0.05 level of significance. RSM was used to obtain optimized extraction conditions, and experiments were run to validate these results.

\section{Anthocyanin profiling by HPLC}

Both DES and methanol extracts were injected on a Synergi $4 \mu \mathrm{m}$ Max-RP C12 column, 80 A, $250 \mathrm{~mm} \times 4.6 \mathrm{~mm}$ (Phenomenex, Torrance, CA, USA) reversed-phase column at $30^{\circ} \mathrm{C}$ using diode array detection (DAD) at $520 \mathrm{~nm}$ (Agilent 1100 Series; Agilent Technologies, Hewlett-Packard, Waldbronn, Germany) (21). The elution was carried out at $0.8 \mathrm{~mL} / \mathrm{min}$ flow rate using water/methanol (90:10) with $1.0 \%$ formic acid $(A)$, and pure methanol with $0.1 \%$ formic acid (B) started at $10 \%$ $B$, increased to $20 \% \mathrm{~B}$ in $7 \mathrm{~min}$, then $45 \% \mathrm{~B}$ in $13 \mathrm{~min}$, up to $70 \% \mathrm{~B}$ in $5 \mathrm{~min}$, ended at $100 \% \mathrm{~B}$ in $3 \mathrm{~min}$ and held for $3 \mathrm{~min}$, and then returned to $10 \% \mathrm{~B}$ in $9 \mathrm{~min}$. Chromatograms were acquired using ChemStation v. A.10.02 software (22). Peaks were identified and quantified by comparing their retention times obtained with those of the standards.

\section{RESULTS AND DISCUSSION}

TAC yield using DES varied between 5.02 and $19.62 \mathrm{mg} / \mathrm{g}$ (Table 1). The final reduced model is shown in the following equation:

$$
\begin{gathered}
w(\mathrm{TAC})=-22.12+0.638 \cdot \mathrm{X}_{1}+0.319 \cdot \mathrm{X}_{2}+0.0748 \cdot \mathrm{X}_{3}+ \\
+0.4554 \cdot \mathrm{X}_{4}-0.00378 \cdot \mathrm{X}_{1}{ }^{2}-0.00452 \cdot \mathrm{X}_{4}{ }^{2}-0.00605 \cdot \mathrm{X}_{1} \cdot \mathrm{X}_{2}
\end{gathered}
$$

where $X_{1}$ is extraction temperature $\left({ }^{\circ} \mathrm{C}\right), X_{2}$ is extraction time (min), $X_{3}$ is volume fraction of water in DES and $X_{4}$ is solvent/ sample ratio $(\mathrm{mL} / \mathrm{g})$. ANOVA results are summarized in Table 2 . It is evident that the lack-of-fit was not significant ( $p>0.05)$, indicating a good fit to the experimental data.

Table 2. ANOVA results of significant factors in quadratic model

$\begin{array}{lrrrrr}\text { Source } & \text { Df } & \text { Adj SS } & \text { Adj MS } & \text { F-value } & \text { p-value } \\ \text { Model } & 7 & 328.000 & 46.857 & 18.07 & 0.0001 \\ \text { Linear } & 4 & 218.185 & 54.546 & 21.04 & <0.0001 \\ \quad \text { Temperature } /{ }^{\circ} \mathrm{C}\left(\mathrm{X}_{1}\right) & 1 & 11.740 & 11.740 & 4.53 & 0.047 \\ t / \mathrm{min}^{*}\left(\mathrm{X}_{2}\right) & 1 & 1.631 & 1.631 & 0.63 & 0.437 \\ \varphi(\text { water }) / \%\left(\mathrm{X}_{3}\right) & 1 & 53.616 & 53.616 & 20.68 & <0.0001 \\ (\text { V/m }) /(\mathrm{mL} / \mathrm{g})\left(\mathrm{X}_{4}\right) & 1 & 145.078 & 145.078 & 55.96 & <0.0001 \\ \text { Quadratic } & 2 & 86.503 & 43.251 & 16.68 & <0.0001 \\ \mathrm{X}_{1}{ }^{2} & 1 & 27.051 & 27.051 & 10.43 & 0.004 \\ \mathrm{X}_{4}{ }^{2} & 1 & 48.513 & 48.513 & 18.71 & <0.0001 \\ \text { Two-way interaction } & 1 & 20.278 & 20.278 & 7.82 & 0.012 \\ \quad \mathrm{X}_{1} \cdot \mathrm{X}_{2} & 1 & 20.278 & 20.278 & 7.82 & 0.012 \\ \text { Error } & 19 & 49.256 & 2.592 & & \\ \text { Lack-of-fit } & 14 & 43.460 & 3.104 & 2.68 & 0.141 \\ \text { Pure error } & 5 & 5.796 & 1.159 & & \\ \text { Total } & 26 & 377.255 & & & \end{array}$

$R^{2}=86.94 \%, R^{2}$ (adj) $=82.13 \%, R^{2}$ (pred) $=69.34 \%$. *In the final model, while time as a single factor is not significant ( $p>0.05$ ), it is significant in the 2-way interaction and is therefore included

Surface plots are shown in Fig. 1. Fig. If shows that high yields are obtained at either a combination of high temperature for short time or at lower temperature for longer extraction time. The optimized extraction conditions are $\mathrm{X}_{1}=75^{\circ} \mathrm{C}$, $X_{2}=10$ min, $X_{3}=90 \%$ water in DES and $X_{4}=50.4 \mathrm{~mL} / \mathrm{g}$, with a predicted TAC response on dry mass basis of $21.3 \mathrm{mg} / \mathrm{g}$. Validation experiments at these conditions resulted in TAC of 19.8 $\mathrm{mg} / \mathrm{g}$. Although anthocyanin degradation is reported at high temperatures (23), the optimal conditions were at the highest temperature $\left(75^{\circ} \mathrm{C}\right)$. Temperature generally contributes to higher extraction yields due to enhanced mass transfer mechanisms (24). In the present study, the chemical environment of the DES system may also have had a positive influence in the thermal stability of the extracted compounds. The main degradation mechanisms related to thermal processing of anthocyanins include oxidation, cleavage of covalent bonds or enhanced oxidation reactions (25), and these processes are influenced by several factors, such as chemical structure of anthocyanins, acylation of the molecule, $\mathrm{pH}$, light, oxygen, temperature, exposure time, presence/activity of enzyme polyphenol oxidase, and presence of other substances (26-28). During thermal processing, these factors may act synergistically, contributing to a higher stability of the bioactive compounds. In the present study, factors such as thermal inactivation of the enzyme polyphenol oxidase and 

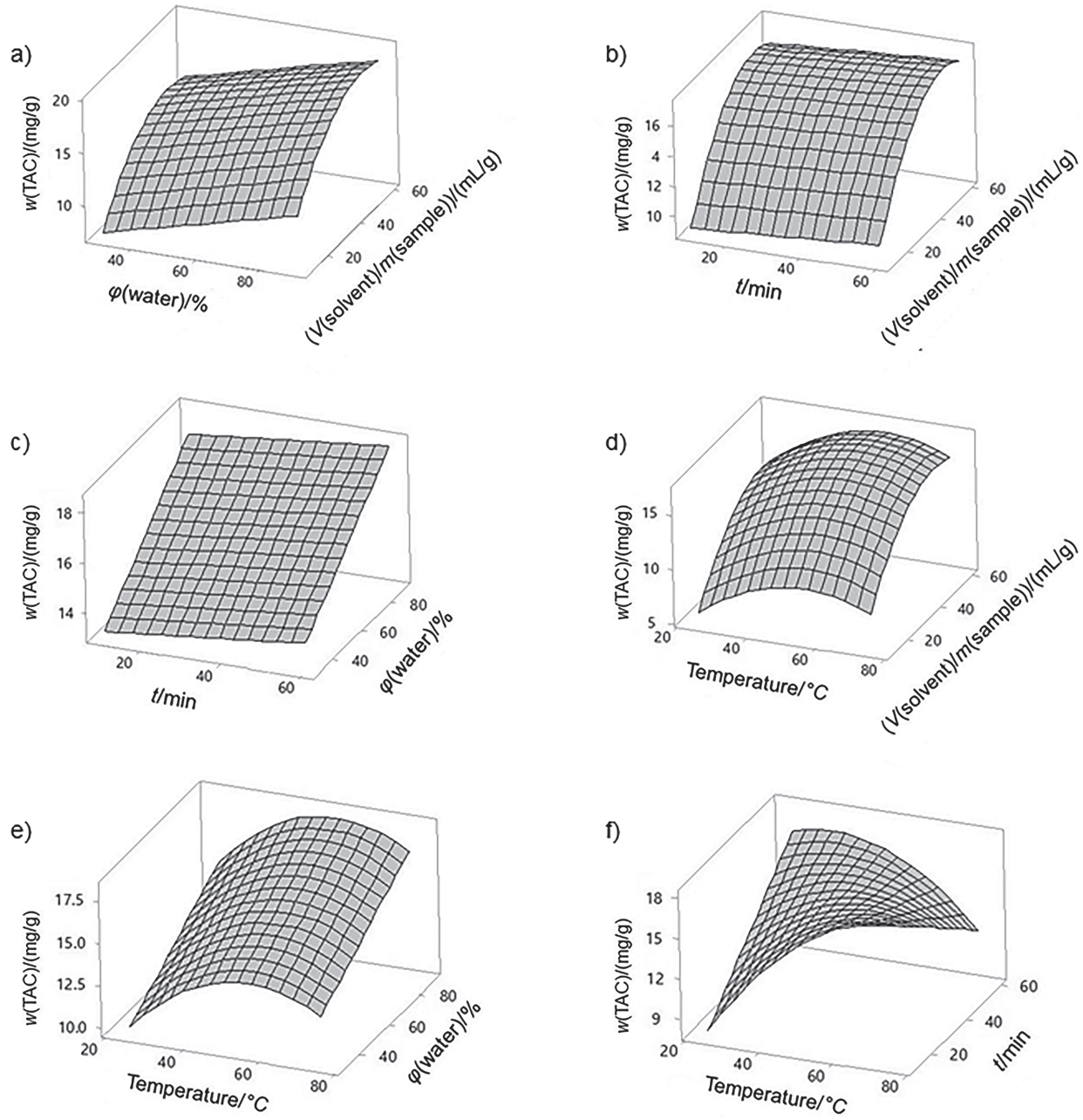

Fig. 1. Surface plots of total anthocyanin content (TAC) extraction: a) $\varphi($ water $) / \% \times(V($ solvent $) / m($ sample) $) /(\mathrm{mL} / \mathrm{g})$, b) $t / \mathrm{min} \times(V($ solvent $) / \mathrm{m}(\mathrm{sam}$ ple) $) /(\mathrm{mL} / \mathrm{g}), \mathrm{c}) t / \mathrm{min} \times(\varphi($ water $) / \%$, d $)$ temperature $/{ }^{\circ} \mathrm{C} \times(V($ solvent $) / \mathrm{m}($ sample $\left.)) /(\mathrm{mL} / \mathrm{g}), \mathrm{e}\right)$ temperature $/{ }^{\circ} \mathrm{C} \times(\varphi($ water $) / \%$, and f $)$ temperature $/{ }^{\circ} \mathrm{C}$ $\times t / \mathrm{min}$

the $\mathrm{pH}$ of the DES system may have contributed to higher stability at high temperature. Furthermore, it is possible that the DES could have caused acylation of the anthocyanin molecule, another factor that improves anthocyanin thermal stability $(25,28)$. Bubalo et al. (29) reported higher extraction of anthocyanins in organic acid-based DES than in DES of lower acidity, achieving optimal UAE yield at $65^{\circ} \mathrm{C}$ for $50 \mathrm{~min}$. The short extraction time needed to achieve optimal yield (10 $\mathrm{min}$ ) is a positive aspect of the process, showing that the DES system can easily access the intracellular structure to promote extraction. Furthermore, the short extraction time would reduce thermal degradation.

The highest water volume fraction (\%) in DES that resulted in the optimum TAC yield was $90 \%$. To ensure that pure water (without DES) was not more efficient, extraction was performed under optimal conditions using $100 \%$ water as the solvent, resulting in a TAC of $17.3 \mathrm{mg} / \mathrm{g}$, significantly lower than optimal DES yield. The increased water volume fraction likely increased the extraction efficiency by decreasing the viscosity of the pure DES, allowing higher access to the plant intracellular structure (24) and higher mass transfer rates (30). This may also indicate a high polarity of the extracted anthocyanins, as more polar anthocyanins are extracted better with DES containing higher water volume fraction $(16,29)$. The high water volume fraction in the solvent has also a positive economic benefit, as it decreases the overall cost of the solvent.

The use of DES to extract anthocyanins from other plant materials has been reported by other researchers. For example, Jeong et al. (13) evaluated the same DES system used in the present work and found it to be an efficient method for extracting anthocyanins from grape skins, when compared with traditional solvents including water, methanol, $80 \%$ aqueous methanol, ethanol and $70 \%$ aqueous ethanol. Radošević et al. (31) and Bosiljkov et al. (14) both used DES made of a combination of choline chloride with malic acid, and found this DES to be more efficient for extraction of anthocyanins than $70 \%$ methanol and acidified ethanol, respectively. Sang et al. (15) used a DES of choline chloride and 1,2-propandiol and found increased anthocyanin extraction 
compared with acidified methanol. Given these results, DES are an effective alternative to methanol for extracting anthocyanins. Previous work conducted by our research group using the same haskap berries (18) showed that conventional extraction using acidified aqueous ethanol ( $80 \%)$ resulted in a TAC yield of $22.73 \mathrm{mg} / \mathrm{g}$. This is comparable to the TAC yield of $19.8 \mathrm{mg} / \mathrm{g}$ from the present study, indicating that similar TAC yields are achieved with this DES system.

The results from HPLC-DAD analysis of DES and methanol extracts from haskap berries indicate that similar anthocyanin profiles were obtained at $520 \mathrm{~nm}$ (Fig. 2). The major component of both extracts was identified as C3GL, which comprises over $80 \%$ total anthocyanins, along with other small amounts of C3RT and P3GL. These data are in accordance with the anthocyanin profile of haskap berries that was reported in a previous study (3). The chromatogram in Fig. 2 suggests that DES had the same anthocyanin-extracting capacity from haskap berries as the conventional acidified methanol.

These results indicate that this DES system is an effective alternative to organic solvents for sustainable anthocyanin extraction. As citric acid and D-(+)-maltose are considered

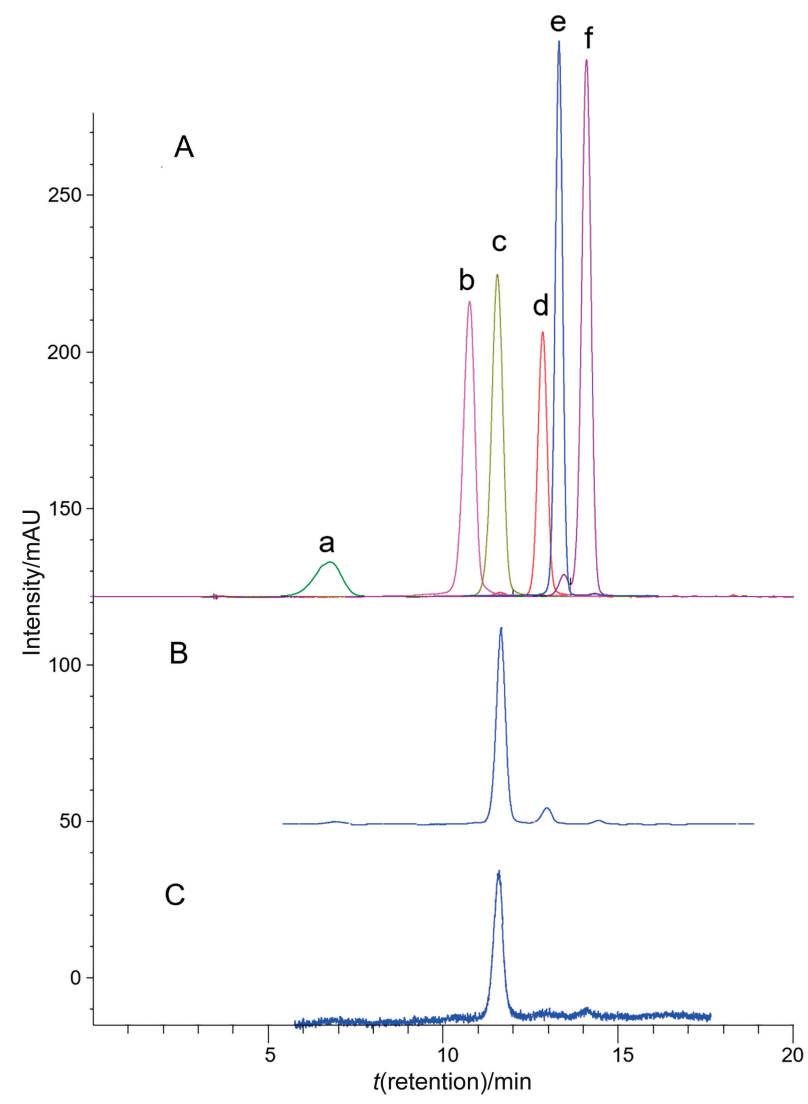

Fig. 2. Anthocyanin profile from HPLC-DAD analysis: $A=$ anthocyanin standards ( $a=$ cyanidin-3,5-di-glucoside $(C 3,5 \mathrm{GL}), b=$ cyanidin-3-galactoside (C3GA), c=cyanidin-3-glucoside (C3GL), d=cyanidin-3-rutinoside (C3RT), e=pelargonidin-3-glucoside ( $P L 3 G L), f=$ peonidin-3-O-glucoside (P3GL)), B=methanol extract, $C=$ deep eutectic solvent (DES) extract
GRAS, this has important implications for the application of DES solvents that are GRAS in the food industry. For example, DES solvents comprising GRAS components could be used to extract bioactive compounds from food processing by-products to increase the sustainability of food production. Apart from that, the DES extracts could be used as novel functional food ingredients and incorporated directly into food products without post-extraction purification, where the DES components may confer additional benefits to the final product. For example, citric acid is an antioxidant and could add to the antioxidant activity of the bioactive compounds in the extract and the final food product.

\section{CONCLUSIONS}

This is the first investigation of anthocyanin extraction from haskap berries using a deep eutectic solvent (DES). Optimized conditions for ultrasound-assisted extraction of total anthocyanins using a citric acid/D-(+)-maltose DES were: extraction temperature $75^{\circ} \mathrm{C}$, extraction time $10 \mathrm{~min}$, solvent/ sample ratio $50.4 \mathrm{~mL} / \mathrm{g}$ and volume fraction of water in DES $90 \%$. The maximum total anthocyanin yield on dry mass basis was $19.8 \mathrm{mg} / \mathrm{g} \mathrm{dm}$, and similar anthocyanin HPLC profiles were obtained with DES and methanol extracts. These results indicate that this DES system is an effective green alternative to organic solvents for sustainable anthocyanin extraction. The prospects for DES extraction in the food industry are promising as they could increase the sustainability of the food industry by utilizing processing by-products and replacing organic solvents with renewable GRAS components. Furthermore, DES extracts using GRAS components could be used as novel functional food ingredients. Future studies should investigate possible chemical interactions between the DES system and the anthocyanins, and the stability of the extracts.

\section{ACKNOWLEDGEMENTS}

The authors would like to thank Dr Azadeh Kermanshahi-pour (Dalhousie University, Halifax, Canada) for providing the HPLC equipment.

\section{FUNDING}

This research was funded by the National Sciences and Engineering Research Council of Canada (NSERC) through its Discovery Grant Program (Account 341213/2013) and Dalhousie University, Halifax, Canada, through its Academic Innovation Fund (AIF). The authors would also like to acknowledge the support from the Department of Foreign Affairs, Trade and Development (DFATD, Canada).

\section{CONFLICT OF INTEREST}

The authors have no conflict of interest to report. 


\section{AUTHORS' CONTRIBUTION}

AM performed the experiments and analysis, drafted the manuscript and designed the figures. YP and GJ provided guidance in the laboratory. MSB supervised the research and obtained funding for the research. AM and MSB planned the research experiments. YP, GJ and MSB aided with the interpretation of data and writing the manuscript. YP and MSB edited and revised the manuscript according to the journal's requirements.

\section{ORCID ID}

Y.P.A. Silva (1) https://orcid.org/0000-0001-5575-0819

M.S. Brooks (1) https://orcid.org/0000-0002-6445-3346

\section{REFERENCES}

1. Bors B, Thomson J, Sawchuk E, Reimer P, Sawatzky R, Sander T. Haskap breeding and production. Final report. Regina, Canada: Agriculture Development Fund, University of Saskatchewan; 2012. Available from: http://www.agriculture. gov.sk.ca/apps/adf/ADFAdminReport/20080042.pdf.

2. Celli GB, Ghanem A, Brooks MS. Haskap berries (Lonicera caerulea L.) - A critical review of antioxidant capacity and health-related studies for potential value-added products. Food Bioprocess Technol. 2014;7(6):1541-54. https://doi.org/10.1007/s11947-014-1301-2

3. Khattab R, Brooks MS, Ghanem A. Phenolic analyses of haskap berries (Lonicera caerulea L.): Spectrophotometry versus high performance liquid chromatography. Int J Food Prop. 2016;19(8):1708-25.

https://doi.org/10.1080/10942912.2015.1084316

4. Panche AN, Diwan AD, Chandra SR. Flavonoids: An overview. J Nutr Sci. 2016;5:e47.

https://doi.org/10.1017/jns.2016.41

5. Khoo HE, Azlan A, Tang ST, Lim SM. Anthocyanidins and anthocyanins: Colored pigments as food, pharmaceutical ingredients, and the potential health benefits. Food Nutr Res. 2017;61:1361779.

https://doi.org/10.1080/16546628.2017.1361779

6. Meireles MA, editor. Extracting bioactive compounds for food products: Theory and applications. Boca Raton, FL, USA: CRC Press; 2008.

https://doi.org/10.1201/9781420062397

7. Wijngaard $\mathrm{H}$, Hossain MB, Rai DK, Brunton N. Techniques to extract bioactive compounds from food by-products of plant origin. Food Res Int. 2012;46(2):505-13.

https://doi.org/10.1016/j.foodres.2011.09.027

8. Chemat F, Vian MA, Cravotto G. Green extraction of natural products: Concept and principles. Int J Mol Sci. 2012;13(7): 8615-27.

https://doi.org/10.3390/ijms13078615
9. Zhang Q, Vigier KDO, Royer S, Jérôme F. Deep eutectic solvents: syntheses, properties and applications. Chem Soc Rev. 2012;41(21):7108-46.

https://doi.org/10.1039/C2CS35178A

10. Cui Q, Peng X, Yao XH, Wei ZF, Luo M, Wang W, et al. Deep eutectic solvent-based microwave-assisted extraction of genistin, genistein and apigenin from pigeon pea roots. Sep Purif Technol. 2015;150:63-72.

https://doi.org/10.1016/j.seppur.2015.06.026

11. Ruesgas-Ramón M, Figueroa-Espinoza MC, Durand E. Application of deep eutectic solvents (DES) for phenolic compounds extraction: Overview, challenges, and opportunities. J Agr Food Chem. 2017;65(18):3591-601.

https://doi.org/10.1021/acs.jafc.7b01054

12. Zainal-Abidin MH, Hayyan M, Hayyan A, Jayakumar NS. New horizons in the extraction of bioactive compounds using deep eutectic solvents: A review. Anal Chim Acta. 2017;979:1-23.

https://doi.org/10.1016/j.aca.2017.05.012

13. Jeong KM, Zhao J, Jin Y, Heo SR, Han SY, Yoo DE, Lee J. Highly efficient extraction of anthocyanins from grape skin using deep eutectic solvents as green and tunable media. Arch Pharm Res. 2015;38(12):2143-52.

https://doi.org/10.1007/s12272-015-0678-4

14. Bosiljkov T, Dujmić F, Cvjetko Bubalo M, Hribar J, Vidrih R, Brnčić $M$, et al. Natural deep eutectic solvents and ultrasound-assisted extraction: Green approaches for extraction of wine lees anthocyanins. Food Bioprod Process. 2017;102:195-203.

https://doi.org/10.1016/j.fbp.2016.12.005

15. Sang J, Li B, Huang YY, Ma Q, Liu K, Li CQ. Deep eutectic solvent-based extraction coupled with green two-dimensional HPLC-DAD-ESI-MS/MS for the determination of anthocyanins from Lycium ruthenicum Murr. fruit. Anal Methods. 2018;10(10):1247-57.

https://doi.org/10.1039/C8AY00101D

16. Dai Y, van Spronsen J, Witkamp GJ, Verpoorte R, Choi YH. Natural deep eutectic solvents as new potential media for green technology. Anal Chim Acta. 2013;766:61-8.

https://doi.org/10.1016/j.aca.2012.12.019

17. Berger PD, Maurer RE, Celli GB. Experimental design: With applications in management, engineering, and the sciences. Cham, Switzerland: Springer International Publishing; 2018.

https://doi.org/10.1007/978-3-319-64583-4

18. Celli GB, Ghanem A, Brooks MS. Optimization of ultrasound-assisted extraction of anthocyanins from haskap berries (Lonicera caerulea L.) using response surface methodology. Ultrason Sonochem. 2015;27:449-55. https://doi.org/10.1016/j.ultsonch.2015.06.014

19. Giusti MM, Wrolstad RE. Characterization and measurement of anthocyanins by UV-visible spectroscopy. Curr 
Prot Food Anal Chem. 2001;00(1):F1.2.1-13.

https://doi.org/10.1002/0471142913.faf0102s00

20. Minitab Statistical Software, v. 17.3.1, Minitab Inc, State College, PA, USA; 2014. Available from: www.minitab.com.

21. Jiao G, Kermanshahi-pour A. Extraction of anthocyanins from haskap berry pulp using supercritical carbon dioxide: Influence of co-solvent composition and pretreatment. LWT - Food Sci Technol. 2018;98:237-44.

https://doi.org/10.1016/j.lwt.2018.08.042

22. ChemStation, v. A.10.02, Agilent Technologies Inc, Waldbronn, Germany; 2009. Available from: https://www.agilent.com/en/products.

23. Verbeyst L, Van Crombruggen K, Van der Plancken I, Hendrickx M, Van Loey A. Anthocyanin degradation kinetics during thermal and high pressure treatments of raspberries. J Food Eng. 2011;105(3):513-21.

https://doi.org/10.1016/j.jfoodeng.2011.03.015

24. Palma M, Barbero G, Piñero Z, Liazid A, Barroso C, Rostagno $M$, et al. Extraction of natural products: Principles and fundamental aspects. In: Rostagno, M, Prado, J, editors. Natural product extraction: Principles and applications. Cambridge, UK: The Royal Society of Chemistry; 2013. pp. 58-88.

https://doi.org/10.1039/9781849737579-00058

25. Patras A, Brunton NP, O'Donnell C, Tiwari BK. Effect of thermal processing on anthocyanin stability in foods; mechanisms and kinetics of degradation. Trends Food Sci Tech. 2010;21(1):3-11.

https://doi.org/10.1016/j.tifs.2009.07.004
26. Rubinskiene M, Viskelis $P$, Jasutiene I, Viskeliene R, Bobinas C. Impact of various factors on the composition and stability of black currant anthocyanins. Food Res Int. 2005;38(89):867-71.

https://doi.org/10.1016/j.foodres.2005.02.027

27. Kırca A, Özkan M, Cemeroğlu B. Effects of temperature, solid content and $\mathrm{pH}$ on the stability of black carrot anthocyanins. Food Chem. 2007;101(1):212-8.

https://doi.org/10.1016/j.foodchem.2006.01.019

28. Ekici L, Simsek Z, Ozturk I, Sagdic O, Yetim H. Effects of temperature, time, and $\mathrm{pH}$ on the stability of anthocyanin extracts: Prediction of total anthocyanin content using nonlinear models. Food Anal Method. 2014;7(6):1328-36.

https://doi.org/10.1007/s12161-013-9753-y

29. Bubalo MC, Ćurko N, Tomašević M, Ganić KK, Redovniković IR. Green extraction of grape skin phenolics by using deep eutectic solvents. Food Chem. 2016;200:159-66. https://doi.org/10.1016/j.foodchem.2016.01.040

30. Dai Y, Rozema E, Verpoorte R, Choi YH. Application of natural deep eutectic solvents to the extraction of anthocyanins from Catharanthus roseus with high extractability and stability replacing conventional organic solvents. J Chromatogr A. 2016;1434:50-6. https://doi.org/10.1016/j.chroma.2016.01.037

31. Radošević $K$, Ćurko N, Srček VG, Bubalo MC, Tomašević $M$, Ganić KK, et al. Natural deep eutectic solvents as beneficial extractants for enhancement of plant extracts bioactivity. LWT - Food Sci Technol. 2016;73:45-51. https://doi.org/10.1016/j.lwt.2016.05.037 